\title{
Paradoxical effects of self-awareness of being observed: testing the effect of police body-worn cameras on assaults and aggression against officers
}

\author{
Barak Ariel $^{1,2}$ - Alex Sutherland ${ }^{3}$. \\ Darren Henstock $^{1}$ • Josh Young ${ }^{1} \cdot$ Paul Drover $^{1}$. \\ Jayne Sykes $^{1} \cdot$ Simon Megicks $^{1} \cdot$ Ryan Henderson $^{1}$ \\ Published online: 18 December 2017 \\ (C) The Author(s) 2017. This article is an open access publication
}

\begin{abstract}
Objectives Recently, scholars have applied self-awareness theory to explain why bodyworn cameras (BWCs) affect encounters between the public and police, with its most immediate manifestation being a reduction in the use of force by and complaints against police. In this study, we report on the paradoxical effects of BWCs in the context of assaults on officers.

Methods A multisite randomized controlled trial in ten departments, with officers wearing (or not wearing) BWCs based on random assignment of shifts. Odds ratios are used to estimate the treatment effect on assaults, along with "one study removed" sensitivity analyses. Further subgroup analyses are performed in terms of varying degrees of officers' discretion, to enhance the practical applications of this multisite experiment. Finally, before-analyses are applied as well, including Bootstrapping and Monte-Carlo simulations to further validate the results under stricter statistical conditions, to illustrate the overall effects.

Results A total of 394 assaults per 1000 arrests occurred during 3637 treatment shifts $(\mathrm{M}=39.35, \mathrm{SD}=17.89)$ compared with 284 assaults per 1000 arrests during 3697
\end{abstract}

Barak Ariel

ba285@cam.ac.uk; barak.ariel@mail.huji.ac.il

Alex Sutherland

alex_sutherland@rand.org

1 Institute of Criminology, University of Cambridge, Sidgwick Avenue, Cambridge CB3 9DA, UK

2 Institute of Criminology, Faculty of Law, Hebrew University, Mount Scopus, 91905 Jerusalem, Israel

3 Communities, Safety \& Justice RAND Europe, Westbrook Centre, Milton Road, Cambridge CB4 1YG, UK 
control shifts $(\mathrm{M}=28.38 ; \mathrm{SD}=15.99)$, which translate into $37 \%$ higher odds of assault in treatment shifts than in control conditions. The perverse direction and relative magnitude in each experimental site in eight out of ten sites were consistent. The backfiring treatment effect was substantially more pronounced in low discretion sites, i.e., where officers strongly followed the experimental protocol $(\mathrm{OR}=2.565 ; 95 \% \mathrm{CI}$ $1.792,3.672$ ). At the same time, before-after analyses show that assaults were overall reduced by $61 \%$ in the participating police departments, thus suggesting paradoxical effects.

Conclusions We explain these findings using self-awareness theory. Once self-aware that their performance is being observed by BWCs, officers become at risk of being assaulted. Results suggest that under some circumstances, self-awareness can lead to excessive self-inspection that strips power-holders of their ability to function under extreme situations. This mechanism is potentially a function of "over-deterrence". The study further demonstrates the benefits of applying psychosocial theories to the study of social control and deterrence theories more broadly, with a robust and falsifiable mechanism that explains the conditions under which being observed stimulates either appropriate or perverse consequences.

Keywords Body-worn cameras · Self-awareness · Deterrence $\cdot$ Being observed · Assaults · Aggression · Police

\section{Introduction}

Psychologists have argued that people modify their attitudes and behavior when they think that others are observing them (Morin 2004, 2011). Once people become cognizant that their demeanor, appearance, or actions are monitored in public, a selfawareness process begins. Self-awareness triggers a complex cognitive process of selfscrutiny and a heightened construction of one's own identity (Wicklund 1975). Evidence of these phenomena is ubiquitous and dates back more than five decades (Duval and Wicklund 1972). More importantly, it is generally agreed that people who are aware of being observed adapt their attitudes and behavior to match what they perceive to be more "acceptable social norms" (Munger and Harris 1989; Sproull et al. 1996) or "socially desirable responses" (Jones and Nisbett 1971; Paulhus 1988).

We examine the application of this line of research to body-worn cameras (BWCs). BWCs are used to videotape interactions between police officers and members of the public in an attempt to "cool down" these encounters. Because BWCs work as thirdparty observers, it is assumed that they elicit the above-mentioned psychosocial processes (Ariel et al. 2015). Although evidence on their effectiveness is beginning to build up, the intended and unintended consequences of using this technology in policing remain unclear (Cubitt et al. 2017, Maskaly et al. 2017, Lum et al. 2015; White and Coldren 2017). The focus in this study is on assaults against police officers, while trying to understand under what conditions BWCs - or self-awareness of being observed-lead to socially desirable behaviors.

Our larger aim is to illustrate the benefits of self-awareness theory in sociology, particularly for deterrence and social control scholars. We argue that these psychosocial mechanisms provide the missing link between real-world deterrence stimuli and 
changes in both attitudes and behavior; this concept has largely been left to crude assumptions in the deterrence literature. More profoundly, whereas deterrence per se is difficult to quantify and observe directly, self-awareness can and has been experimentally induced. Therefore, self-awareness is not only a phenomenological concept but is also susceptible to manipulation to the point that society can utilize this body of knowledge in the regulation of behavior. BWCs are one such stimuli.

The paper is structured as follows. First, we review relevant literature on self-awareness, being observed, and consequent socially desirable responses. We then discuss how these are potentially linked to deterrence theory. We next present the state of the art of the evidence on BWCs, including the possible moderating factors that constrain or exacerbate the effect of BWCs in police-public encounters. We subsequently discuss the hypothesized effect of BWCs on assaults against police officers. The research design and analytical strategy used to test these hypotheses are described in the methods and data section, followed by an exposition of the results. Based on the use of an experimental design across ten participating police departments, we defend the view that our causal estimates are robust. We present a complex story about the effect of BWCs on assaults on officers. We found a significant before-after reduction in assaults, whereas the between-group comparisons yielded a perverse result: greater odds of assaults against officers who use BWCs than the odds under control conditions. Subgroup analyses are used to explain these paradoxical effects. We suggest that the underlying mechanism is police discretion: weak discretion in the use of BWCs and the application of police force is linked to more assaults. It seems that BWCs may cause "over-deterrence," and officers may become hesitant to apply necessary force, which in turn results in more assaults. Instead of using force to subdue hostile suspects following a split-second decision, some officers are reluctant to use force due to fear of reprimands for using any type of force inappropriately. This phenomenon represents a "dark side" of self-awareness that was previously unknown.

\section{Theoretical framework}

\section{Self-awareness}

Self-awareness refers to the process of focusing attention inward toward the self (Mead 1934), or the capacity of becoming the object of one's own attention. One becomes self-aware when one reflects on the experience of perceiving and processing stimuli. Intuitively, many of us are familiar with this feeling; merely being in front of an audience induces self-awareness (Buss 1980). However, self-awareness represents a complex multidimensional phenomenon that comprises many domains and corollaries (Eilan et al. 1995; Morin 2011; Wicklund 1975). ${ }^{1}$

\footnotetext{
${ }^{1}$ There is a distinction between "two aspects of the self - the public self and the private self. The public self consists of the overt, externally observable aspects such as physical appearance. Conversely, the private self entails the covert aspects, that is, those aspects of the self that cannot be observed by others." (Froming et al. 1982: 477). The most widely known manipulations used to exert public self-awareness are mirrors, while audiences are often used to achieve private self-awareness. Our work does not aim to ascertain on which type of psychological mechanism BWCs "work". It is possible that BWCs can be viewed as a manipulation that can engage both types of self-awareness, or more on each in some circumstances but less in other circumstances. Future research should explore this distinction more robustly.
} 
Duval and Wicklund (1972) showed that self-awareness could be experimentally induced. Their findings demonstrated that self-awareness is not only a phenomenological concept but also a psychosocial (as well as neurological) process that society can utilize in the regulation of behavior. We now know that a wide range of stimuli can trigger self-awareness (Butterworth 1992, 1995; Cole and Stewart 1999). Specific "self-focusing stimuli" such as cameras, audiences, recordings, and mirrors have been tested in controlled settings to stimulate self-awareness (Buss 1980; Carver and Scheier 1978; Davis and Brock 1975; Davis and Franzoi 1991; Geller and Shaver 1976; Morin 2002). For example, with mirrors, the reflection provides a source of feedback that allows the individual to adjust her or his presentation to convey a desired image to those around her or him (Gervais and Norenzayan 2012). Collectively, studies have shown that by inducing this process of self-awareness, we become aware of our "selfdomains" (e.g., self-criticism, self-efficacy) as well as our "public self-dimensions," such as our own behaviors, mannerisms, and appearance (Duval and Wicklund 1972). A substantial body of research supports the basic concept in social psychology that being self-aware triggers a cognitive process of self-scrutiny and a heightened construction of one's identity (see review in Froming et al. 1982).

The evidence on the effects of increased self-awareness on behavior is broad and extensive. A prominent and objective outcome of self-awareness is the adaptation of behavior (Chartrand and Bargh 1999; Dzieweczynski et al. 2006; Heine et al. 2008; Jones and Nisbett 1971; Morin 2005). Some of the behavioral manifestations found in previous research are avoidance (Moskalenko and Heine 2003), self-harm (Baumeister 1990; Morin and Craig 2000), increased emotional intensity (Silvia 2002), andparticularly pertinent to our research-self-regulation (Bandura 1978; Carver and Scheier 2004; Kanfer 1977). Self-regulation includes "altering one's behavior, resisting temptation, changing one's mood, [and] selecting a response from various options" (Morin 2011: 814). Note that these are dimensions within the self that are perceived as requiring control.

When thinking about how increased self-awareness leads to socially desirable responses, research findings generally agree that individuals react in socially desirable ways to even the slightest cues indicating that someone may be watching (Bateson et al. 2006; Boyd et al. 2010; Burnham and Johnson 2005; Haley and Fessler 2005; but cf. Northover et al. 2017). Therefore, self-awareness of being observed heightens the need to cooperate with rules (Barclay 2004; Milinski et al. 2002; Wedekind and Braithwaite 2002).

Most sociologists should feel at home with real-world displays of the process that leads to socially desirable behavior (i.e., self-awareness of being observed) because, thus far, we have described the psychosocial mechanisms behind deterrence theory (Jervis 1989; Tibbetts 2013; for more recent explorations of moderators of being observed and socially desirable behavior, see Pfattheicher 2015; Pfattheicher and Keller 2015). Knowing with sufficient certainty that our behavior is being observed or judged affects social cognitive processes that make us comply with codes of desirable behavior. These codes are often found in law and regulations or in the socially desirable responses in social interactions mentioned previously (Ariel et al. 2015). Deterrence theory offers the requirement of a heightened level of appreciation that not only is someone observing our behavior but that the observing entity will punish us for transgressions. At a high level of abstraction, there is ample evidence that the perceived 
certainty of punishment is causally associated with less rule-breaking (Ariel and Partridge 2016; Bushway and Reuter 2008; Lochner 2003; Loughran et al. 2012; McCord and Conway 2002; Nagin 2013a; Nagin 2013b; Paternoster 2010; Pratt et al. 2006; but cf. Berk and MacDonald 2010; Tonry 2008; Wikström and Treiber 2007). More than the severity of sanctions and probably more than the celerity of sanctions (Von Hirsch et al. 1999), increasing the perceived likelihood of being caught is inversely linked to the likelihood of breaking rules. This "certainty effect" carries wide probabilities over a range of settings in which society attempts deterrence (Nagin 2013a).

\section{Body-worn cameras}

One stimulus that has recently been proposed to encourage self-awareness and lead to socially desirable behavior is police BWCs. The police have enthusiastically endorsed BWCs, as have politicians, civil rights advocates and the public (Obama 2015). This interest has generated a growing multibillion-dollar industry (Sutherland and Ariel 2016). BWCs are small audio-video recorders that are "mounted" on police officers. They have two overarching goals. On the one hand, by recording police-public interactions from the officer's perspective, BWCs are believed to prevent escalations or new crimes from occurring (White 2014), as well as protect officers from violating rules of conduct. On the other hand, they may assist in bringing offenders to justice (Morrow et al. 2016). Once suspects become (or are made) aware of the cameras, and officers are reminded about the cameras, a deterrent effect is hypothesized for those present in the encounter: "Look out! You are on camera" (Jennings et al. 2015; Ready and Young 2015).

Theoretically, the deterrence message may work to change behavior in different ways. For example, the camera and verbal prompt could lead to increased selfawareness for both officers and suspects, which in turn leads to a greater level of rational-deliberative action (including calculations of risks of sanction threat/punishment), increasing self-regulation/behavioral inhibition, and perhaps a closer adherence to rules of conduct (Ariel et al. 2015: 516 Ariel 2016). Since the risk of apprehension for misconduct, hostile, or criminal behavior is elevated to near certainty (when the cameras are turned on), both parties are believed to "cool off" (Ariel 2016a). The "belligerent" suspect is expected to become less resistant, and the "thin-skinned" police officer is expected to respond more professionally, demonstrating fairness, dignity, and respect and using proportional force only when necessary (Bottoms and Tankebe 2012; Tyler 1990; Tyler and Lind 1992). Conversely, it may be that the cameras primarily nudge the suspect toward being more deliberative, and that in turn changes the overall tenor of the interaction, and it is speculation as to whether self-regulation does matter. At the same time, the speed with which such interactions take place, and the very fact they are reciprocal in nature, means that existing research is unable to answer questions about who is more affected by the cameras.

Evidence of BWCs' effectiveness has surfaced only in the last few years. A recent literature search of the available evidence conducted by Lum et al. (2015) reported on 12 published studies of BWCs. The review concluded that there were too few studies to draw firm conclusions, but that there were some emerging areas relating to the possible 
effects of cameras on complaints, accountability, stop and frisk, arrest, and use of force (to name but a few). ${ }^{2}$

\section{Moderating factors}

Since the Lum et al. (2015) review, additional research has been published that tries to explain the conditions under which BWCs work. The self-awareness effect of BWCs is conditional on the extent to which the cameras are activated (Hedberg et al. 2017; Taylor 2016; Young and Ready 2016), which is unsurprising: if officers choose to not turn the cameras on, the mechanism that causes self-awareness and the cognitive process of self-scrutiny will not materialize. The prerequisite condition is ensuring that officers activate the cameras. However, a major contributing factor to patterns of police officers' attitudes and behaviors, including the use of force, complaints against the police, or injuries in the line of duty, is the institutional subculture (Blau and Blau 1982; Galliher 1971; Herbert 1998; Sherman 1980; Waddington 1999). Police "in-group" cohesion is preserved by styles with a "common vision that becomes part of each officer's mindset of how to handle everyday aspects of policing" (Terrill 2001: 20). This means that officers tend to react similarly to given situations because of organizational operating procedures, incentives, and top-down managerial and bottom-up behavioral models (Sherman 1980; Wilson 1968, Tankebe 2016). An ethos and mutual conceptualization of reality thus develops in any police department that may include the tacit approval of certain actions that are otherwise inappropriate (Brown 1998; Skolnick 2008).

Police subculture is relevant to BWC research because so-called "big-brother little nudges", intrusions into day-to-day operations, are believed to cause wide departmental effects. Ariel et al. (2016a) have reported direct evidence that repeated and systematic exposure to a stimulus that elicits deterrence can increase accountability, even when the stimulus is removed. Through repeated exposure to the surveillance effect of the cameras, police officers learn what normative or appropriate reactions are, even when they are no longer under surveillance (during control conditions). This may be true for officers who once wore BWCs and no longer wear them (through the process of random assignment) or officers in the department who did not take part in the experiment (e.g., neighborhood police teams, special victim support units). Ariel et al. (2016b) argued that BWCs affect entire police departments through a process they labeled "contagious accountability." Everyone is affected by the BWCs, even

\footnotetext{
${ }^{2}$ As summarized in the report, "We refrain at this point from drawing any definitive conclusions about BWCs from the twelve existing studies because there are so few of them. Individually, nonetheless, these studies are beginning to hint at a few possible hypotheses. For example, it appears that officers may not necessarily have negative attitudes toward BWCs generally (see, e.g., Jennings et al. 2014; Owens et al. 2014; Ellis et al. 2015). However, some of the studies examining activation of the cameras find varying levels and nuances of compliance and activation of cameras (see Roy 2014). BWCs may reduce complaints against the police (see Ariel et al. 2015; Goodall 2007; Katz et al. 2014) or result in quicker resolution of complaints (see Katz et al. 2014; ODS Consulting 2011). However, whether or not that signals increased accountability, improved citizen satisfaction, or improved police or citizen behavior is still uncertain [...] Ariel et al. (2015) find that $B W C$ s reduce use of force incidents, but find that arrest activity increases for officers wearing BWCs (Owens et al. 2014 also seem to find similar impacts on individuals being charged). Interestingly, Ready and Young (2015) seem to find that officers wearing cameras, while less likely to perform stop and frisks or make arrests, are more likely to give citations." (p. 11)
} 
when the cameras are not in use; thus, the subculture has become less aggressive and more compliant with procedures.

\section{Use of BWCs to reduce assaults against police officers}

It is logical to assume that when officers use BWCs, they should be assaulted less frequently. If BWCs can "cool off" aggressive encounters (Ariel et al. 2015; Jennings et al. 2015; Sutherland 2017), they are also likely to reduce the likelihood of assaults against the police. An individual who assaults an officer may be shot (in the US, at least), but the individual will almost certainly be punished more severely if the event can be proved in court. Therefore, rational suspects would avoid assaulting officers when the likelihood of apprehension for assaulting an officer is high (Whichard and Felson 2016). This is the case for BWCs: the probability of being caught assaulting a police officer is substantially increased because a camera pointing at the transgressor provides unequivocal evidence of the assault. The assumption is therefore that reasonable offenders will not want to be caught and subsequently punished for misbehavior (Margarita 1980; Ojedokun 2014). In turn, the officer is also less likely to act in ways that would provoke the suspect, which in turn will cause the officer to respond in a nonprofessional way. As both parties become aware that the camera is observing them, the elevated selfregulation mechanism is hypothesized to reduce the need to apply forceful police responses. Consequently, assaults on officers should be minimized.

Before testing this hypothesis, it is important to contextualize the scope, prevalence, and taxonomy of assaults against the police, on which, collectively, the literature seems somewhat unclear (Bierie 2015). Many studies suggest that approximately $10 \%$ of officers are injured during use-of-force incidents (Henriquez 1999; Kaminski 2004; Kaminski et al. 2004; Smith and Petrocelli 2002; Smith et al. 2007), but some studies have observed rates of up to $38 \%$ (Alpert and MacDonald 2001; Kaminski and Sorensen 1995). Recorded injuries are relatively minor in terms of severity (Alpert et al. 2000; Brandl 1996; Brandl and Stroshine 2003; Kaminski 2004). The most common cause of injury to officers during arrest is when officers attempt to subdue a suspect with bodily force (punching, kicking, take-downs, wrestling and joint locks); these techniques account for most recorded injuries (Kaminski and Sorensen 1995; Meyer 1992; Smith and Petrocelli 2002). Kaminski and Sorensen (1995) found that officers are more likely to suffer an injury during an incidence of use of force if they are employing levels of force at the lower end of the "force continuum" (Garner et al. 1995), such as "hands-on tactics" that require close contact with a suspect (see also Fryer 2016).

\section{Methods and data}

Settings Ten police departments adopted the same experimental protocol to test the effect of BWCs on assaults against the police under controlled conditions. Although a convenience sample of police departments should not be construed as representative of the entire population of police departments, the results from a ten-site design in six 
Table 1 Descriptive statistics for the ten participating sites

\begin{tabular}{llllll}
\hline Site & Population size & $\begin{array}{l}N \text { of } \\
\text { shifts }\end{array}$ & $\begin{array}{l}N \text { of frontline officers } \\
\text { during the trial }\end{array}$ & $\begin{array}{l}\text { Officer hours } \\
\text { during trial }\end{array}$ & $\begin{array}{l}\text { Follow-up period } \\
\text { post-RA (in weeks) }\end{array}$ \\
\hline Site A & 161,400 & 1,107 & 546 & 221,760 & 22 \\
Site B & 285,700 & 270 & 23 & 9,112 & 26 \\
Site C & 203,800 & 1,107 & 111 & 410,256 & 22 \\
Site D & 285,700 & 268 & 22 & 9,112 & 26 \\
Site E & 751,500 & 1,107 & 870 & 369,600 & 22 \\
Site F & 188,400 & 784 & 120 & 235,200 & 52 \\
Site H & 108,817 & 734 & 115 & 176,160 & 50 \\
Site I & 26,757 & 844 & 60 & 494,640 & 45 \\
Site J & 151,533 & 225 & 150 & 135,000 & 45 \\
Site K & 249,470 & 888 & 105 & 127,872 & 43 \\
Grand Total & $\mathbf{2 , 1 2 7 , 3 7 7}$ & $\mathbf{7 , 3 3 4}$ & $\mathbf{2 , 1 2 2}$ & $\mathbf{2 , 1 8 8 , 7 1 2}$ & $\mathbf{3 5 3}$ \\
M & $\mathbf{2 3 6 , 3 7 5 . 2 2}$ & $\mathbf{7 3 3 . 4}$ & $\mathbf{2 1 2 . 2 0}$ & $\mathbf{2 1 8 , 8 7 1 . 2 0}$ & $\mathbf{3 5 . 3 0}$ \\
SD & $\mathbf{2 0 7 , 4 7 0 . 2 1}$ & $\mathbf{3 5 7 . 0}$ & $\mathbf{2 7 5 . 4 4}$ & $\mathbf{1 6 3 , 5 7 3 . 9 9}$ & $\mathbf{1 2 . 6 8}$ \\
\hline
\end{tabular}

RA = Random Assignment. Site codes used to mask research location; ^annualized

jurisdictions and two English-speaking countries provide a robust framework for testing the effect of self-awareness on assaults against the police on the one hand, or aggression by the police on the other. Table 1 provides the basic descriptors of each site (two separate geographic areas were included in the trial; hence, there is a greater number of trials than police forces). The total number of residents policed across the ten jurisdictions that took part in this study was above 2 million. During the study period, a total of 2122 officers made more than 15,600 arrests.

Random assignment Beyond large-scale cluster-randomized designs, randomizing shifts is the most practical approach to implementing BWC trials with the police because even small forces can leverage a large sample size. ${ }^{3}$ Each study was a twoarmed trial that randomly assigned officer shifts to either experimental (with cameras) or control (no cameras) conditions on a weekly basis using the Cambridge Randomizer

\footnotetext{
${ }^{3}$ We acknowledge that this unit of analysis (the shift) has produced some level of treatment contamination, which prima facie violated the Stable Unit Treatment Value Assumption (Cox 1958; on SUTVA). In principle, this means a lack of separation between treatment and control units, a scenario that can create problems when assessing the causal inference of the intervention. As the same officers either used BWCs or did not use BWCs in treatment and control shifts, respectively, any possible change in the behavior of the officers due to the intervention affected control conditions as well. One mechanism that can explain this bias is learning theory (Ariel 2016; Maskaly and Donner 2015:221): A learned behavior adapted into socially-desirable conduct under treatment conditions of surveillance is carried through to control conditions in which the intervention per se has been removed. Assuming the officer confirms with the socially-accepted behavior that s/he manifested during treatment shifts, and assuming s/he internalizes that this behavior is expected of her/him all the time, the diffusion of treatment can be seen as instrumental conditioning. These socially-acceptable behaviors followed by satisfying consequences will be repeated, while those that lead to unsatisfying consequences are less likely to be repeated. Hence, the more exposure to the expected behaviors during treatment conditions, which tends to be reinforced given the civilizing effect of the BWCs, the more of an effect will be measured in control conditions.
} 
(Ariel et al. 2012). This means that the shift is the unit of analysis, not individual officers as with other BWC studies. Weekly sequences of treatment and control shift were communicated to the patrol officers. Shift randomization resulted in 4264 shifts being assigned $(\mathrm{M}=609.1 ; \mathrm{SD}=264.0$ per site $)$, with equal allocations of day and

\section{(continued)}

Despite this potential bias, it is still the case that officers in control conditions did not wear BWCs; they were certainly aware that the results of their actions and conduct are under surveillance in both treatment and control outcomes, yet this awareness to potential surveillance is not synonymous to a "credible deterrent threat." Every recorded interaction can be viewed, audited, and then lead to a reprimand, but an unrecorded interaction does not necessarily lead to similar costs (a recorded incident of excessive use of force can very likely lead to criminal prosecution of the officer, while an unrecorded incident of excessive use of force can more 'easily' be left to subjective interpretations - and we should expect officers to be acutely aware of this distinction). In deterrence theory terms, the perceived likelihood of apprehension is substantially elevated in treatment conditions than control conditions. While under both experimental arms the behavior may have been modified as a result of the spill-over, the extent of the behavioral modification under control conditions cannot be assumed to be the same as that which has taken place under treatment conditions - otherwise we would not observe significant differences between treatment and control conditions across multiple outcomes, using this research design (e.g., Ariel et al. 2015; Ariel et al. 2016a; Ariel et al. 2016b). For these reasons, Ariel et al. (2017) were mistaken when giving a medical analogy for this treatment contamination ("both groups are taking the pill"). Instead, a more suitable analogy in these circumstances is that both groups are assigned to take the pill, but only the treatment group is required to do it front of a camera in order to make sure the patients swallow the pill.

In addition to this practical justification that carries methodological implication as well, we stress that our design explicitly creates risks to Type II error rather than Type I error. A statistical Type I error would indicate that that the null hypothesis is rejected when it ought to be not rejected (false positive), while Type II error implies the mirror image of Type I — that the null hypothesis is not rejected when it ought to be rejected (false negative). In practice, using the shift as the random assignment, with the potential of cross-units contamination, means that it becomes more difficult to reject the null hypothesis of differences between treatment and control conditions. As both arms of the trial are exposed to some level of the manipulation (at least as it is applied to the officers), it becomes more challenging to detect statistically significant differences. Hence, if anything, a statistically significant difference between the experimental and control arms, under these conditions, implies that the true treatment effect is more pronounced.

Finally, one must consider alternative designs. We assert that these SUTVA concerns are less of a problem in our research design than in experiments in which the unit of analysis is the individual officer (e.g., Jennings et al. 2015). With person-based experiments, at least in trials of BWCs but probably beyond that as well, the extent of the cross-units contamination is in fact more challenging to overcome and presents even more strenuous settings for causal inference. In the person-based experiments, different officers wear BWCs or not, and in theory the bias is then minimized. However, the level of treatment contamination in police-public interactions becomes detrimental to the study: in singleofficer suspect interactions, this is less of a concern, but in nearly every high-profile policing incident (such as the use of force, serious harm, multiple offenders, etc.), at least two officers would attend the call, and some of the officers might be 'treatment officers' while others might be 'control officers'. In this situation, should we assume that every officer is a 'treatment officer' because one of the officers in the scene is video-recording everybody else? How should we interpret a multiple-officer interaction? Furthermore, given the heightened risk to officers' safety, currently most police departments instated a policy of mandatory patrols in duos or more, so the unit of analysis should be the 'patrol unit' or the squad, not the individual officer; but thus far, person-based experiments have neglected this issue. The contaminated units might be qualitatively different from the uncontaminated units, and this creates theoretical challenges in interpreting the results - especially when thus far the participating officers in the person-based BWCs experiments have been volunteering officers (Jennings et al. 2015; see also Ready and Young 2015). 
night shifts, including days of the week (see Table 2). No differences were observed between the treatment and control conditions in terms of the distribution of shifts. ${ }^{4}$

\section{Treatment and control conditions}

The pre-published protocol agreed upon with each police department stated that officers on "camera on" shifts had to keep the cameras on during their entire shift (typically 8 $12 \mathrm{~h}$ ) and inform members of the public during any encounter that they were wearing a camera that was recording their interaction. This means that the intervention consisted of \{camera + notification $\}$ (on the importance of the interaction between these elements, see Sunstein and Thaler 2008; Sunstein 2014). The trial design meant that officers were not supposed to exercise discretion in deciding when cameras were turned on. The cameras were assigned to be on throughout their shift with every interaction with members of the public. However, in some instances officers did not record using devices between jobs (e.g., when traveling between calls for service) and while on restbreaks. The only pre-agreed exceptions to interactions being recorded was when officers responded to specific types of incidents, as pre-agreed with senior staff in each force (e.g., when conversing with informants, serious sexual assaults, or major public events). Where officers were not recording between jobs, many devices have a "preevent buffer" that continuously captures up to $2 \mathrm{~min}$ before officers press "record" on the device, meaning that the lead-up to a response should also be captured.

\section{Treatment fidelity and manipulation checks}

Maintaining consistent treatment integrity across several sites is a challenge in experimental criminology (see MacKenzie et al. 2013; de Brito 2017; Slothower et al. 2015; Weisburd and Taxman 2000). To address risks to fidelity, each trial was managed by a local researcher (see Drover and Ariel 2015). Routinely collected metadata captured by the BWCs, such as how much data had been recorded, along with date and time stamps, were also used to measure treatment integrity (see Table 3). Cross-tabulating between the date and time of evidence uploaded from the BWCs and random assignment provides a direct measure of manipulation checks. Any footage recorded during control shifts was considered a violation of the protocol - that is, a sign of noncompliance. A control shift with at least 1 minute of recorded footage was considered a breach of protocol, as BWCs should not have been taken out of the police station during control shifts. Conversely, when cameras recorded 0 minutes of data during a shift, this was an indication that the camera had been switched off or unused during the shift. This scenario was considered a violation of the experimental protocol as well, as it is unreasonable that any response officer on duty would have no recordable interaction. These are "Empirical Checks" of the manipulations, of which an example can be found in Supplementary Materials.

In addition, there were explicit circumstances where treatment integrity was compromised: when the police department openly announced the breakdown, a few months into the experiment. This means that officers in these experimental sites initially

\footnotetext{
${ }^{4}$ Following CONSORT guidelines, we did not test statistically for differences between trial conditions (http://www.consort-statement.org/checklists/view/32-consort/510-baseline-data).
} 
Table 2 Trial measures by treatment allocation within each participating site

\begin{tabular}{lllllllllll}
\hline Site $\times$ day of week & Site J & Site I & Site A & Site C & Site E & Site B & Site D & Site K & Site F & Site H \\
\hline Cameras on & $\mathbf{3 3 7}$ & $\mathbf{8 8}$ & $\mathbf{2 2 9}$ & $\mathbf{2 3 2}$ & $\mathbf{2 2 9}$ & $\mathbf{6 6}$ & $\mathbf{6 2}$ & $\mathbf{4 4 5}$ & $\mathbf{3 9 2}$ & $\mathbf{3 6 7}$ \\
Monday & 68 & -- & 33 & 34 & 32 & 10 & 11 & 66 & 56 & 52 \\
Tuesday & 67 & -- & 33 & 33 & 32 & 8 & 9 & 64 & 56 & 52 \\
Wednesday & 67 & -- & 32 & 33 & 33 & 9 & 9 & 64 & 56 & 52 \\
Thursday & 69 & -- & 33 & 33 & 33 & 11 & 8 & 61 & 56 & 54 \\
Friday & -- & 44 & 32 & 33 & 33 & 9 & 7 & 62 & 56 & 52 \\
Saturday & -- & 44 & 33 & 33 & 33 & 8 & 8 & 65 & 56 & 53 \\
Sunday & 66 & -- & 33 & 33 & 33 & 11 & 10 & 63 & 56 & 52 \\
No cameras & $\mathbf{3 3 8}$ & $\mathbf{9 2}$ & $\mathbf{2 3 3}$ & $\mathbf{2 3 0}$ & $\mathbf{2 3 3}$ & $\mathbf{6 8}$ & $\mathbf{7 2}$ & $\mathbf{4 4 3}$ & $\mathbf{3 9 2}$ & $\mathbf{3 6 7}$ \\
Monday & 67 & -- & 33 & 32 & 34 & 10 & 9 & 63 & 56 & 52 \\
Tuesday & 68 & -- & 33 & 33 & 34 & 11 & 10 & 65 & 56 & 52 \\
Wednesday & 68 & -- & 34 & 33 & 33 & 11 & 11 & 62 & 56 & 52 \\
Thursday & 66 & -- & 33 & 33 & 33 & 8 & 11 & 65 & 56 & 52 \\
Friday & -- & 46 & 34 & 33 & 33 & 10 & 12 & 64 & 56 & 54 \\
Saturday & -- & 46 & 33 & 33 & 33 & 10 & 10 & 61 & 56 & 53 \\
Sunday & 69 & -- & 33 & 33 & 33 & 8 & 9 & 63 & 56 & 52 \\
Grand total & $\mathbf{6 7 5}$ & $\mathbf{1 8 0}$ & $\mathbf{4 6 2}$ & $\mathbf{4 6 2}$ & $\mathbf{4 6 2}$ & $\mathbf{1 3 4}$ & $\mathbf{1 3 4}$ & $\mathbf{8 8 8}$ & $\mathbf{7 8 4}$ & $\mathbf{7 3 4}$ \\
\hline & & & & & & & & & \\
\hline
\end{tabular}

Site codes used to mask research locations

followed protocol, but then were granted discretion to wear, use, and record incidents, despite the experimental protocol. The protocol dictated that every encounter was to be videotaped as soon as the officer interacted with the suspect, witness, or victim during treatment shifts, but never to be used during control shifts. ${ }^{5}$ However, some time after the trial commenced, some departments intentionally violated the protocol in some ways. This announcement/noncompliance took two forms: first, when the police department announced that officers were allowed to use the devices during both control shifts as well as treatment shifts, as they deemed fit. This occurred approximately 90 days into the trials. These are sites that can be characterized as lacking treatment integrity, because there were de facto no differences between treatment and control conditions shortly after the experiment commenced, in terms of the application of the manipulation. The rationale given for this breakdown was in the context of operational needs: when the sponsoring officer has taken the view that the initial testing period was sufficient for him/her to make a decision to deploy the devices as business-as-usual. We refer to these circumstances as "police-announced breakdown."

A second type of noncompliance announcement characterized other departments: full compliance with the protocol in terms of control conditions, but failure to comply with the terms of treatment conditions. Despite the evidence against this policy (see

\footnotetext{
${ }^{5}$ There were some pre-agreed types of cases where officers were allowed to switch off cameras - such as serious sexual violence cases or dealing with informants - but otherwise officers were required to keep cameras on throughout their shifts and record every interaction with suspects, witnesses, and victims.
} 
Table 3 Breakdown of sites based on treatment integrity

\begin{tabular}{|c|c|c|}
\hline Site & Indication of treatment integrity & Compliance subgroups \\
\hline Site A & Police-announced breakdown & No compliance \\
\hline Site B & Empirical check & High compliance \\
\hline Site C & Police-announced breakdown & No compliance \\
\hline Site D & Empirical check & High compliance \\
\hline Site E & Police-announced breakdown & No compliance \\
\hline Site F & Police-announced breakdown & No compliance \\
\hline Site $\mathrm{H}$ & Empirical check & High compliance \\
\hline Site I & $\begin{array}{l}\text { Police-announced breakdown in treatment } \\
\text { group }+ \text { empirical check }\end{array}$ & $\begin{array}{l}\text { Compliance within control } \\
\text { group only }\end{array}$ \\
\hline Site $\mathrm{J}$ & $\begin{array}{l}\text { Police-announced breakdown in treatment } \\
\text { group }+ \text { empirical check }\end{array}$ & $\begin{array}{l}\text { Compliance within control } \\
\text { group only }\end{array}$ \\
\hline Site K & $\begin{array}{l}\text { Police-announced breakdown in treatment } \\
\text { group }+ \text { empirical check }\end{array}$ & $\begin{array}{l}\text { Compliance within control } \\
\text { group only }\end{array}$ \\
\hline
\end{tabular}

Hedberg et al. 2017; Roy 2014), some departments gave officers the discretion to use BWCs how and when they deemed fit during treatment condition - that is, which interactions were worthy of recording, at which point during the police-public interaction to turn the cameras on or off, and whether or not to announce the recording of the interaction. Two major reasons for this decision were technological and/or financial: the battery life of the camera did not allow recording of every interaction, and the cost of uploading data, and the storage of the data exceeded the department's budgetary constraints. At the same time, officers were instructed and subsequently followed the protocol in terms of control settings: devices were not to be used during "cameras off" shifts. Failing that, these circumstances can be seen as "Police-announced breakdown in Treatment Group."

Outcome variables We were granted access to official records of assaults on officers through a data-sharing agreement with each department. Because not all sites completed a 12-month trial, the assault counts were annualized for comparability purposes (Table 1). To clarify, assaults were defined as reports by the officers themselves before any internal investigation into the incident had been made. Officers can report assault for a wide range of reasons, including physical injuries and verbal abuse. Data-sharing issues meant that we were not given access to the types of assault but only to the total number of assaults during each shift (a point we return to in the discussion).

Statistical procedure We used the Comprehensive Meta-Analysis Version 2 software (CMA) to synthesize the between-group results from the trials and present the overall results as a function of rates of assaults against the police per 1000 arrests. Because each trial used the same design and outcomes, it was appropriate to combine and report them as a prospective meta-analysis (Lipsey and Wilson 2001). The data inputted into CMA consisted of the rates of assaults per 1000 arrests in (i) control shifts and (ii) treatment shifts. We converted these rates into odds ratios to compare treatment and 
control conditions across all sites, and used the corresponding 95\% confidence intervals as a measure of the reliability of the estimation procedure (Cohen 1988).

We verified the consistency of the meta-analytical results by measuring the influence of individual sites on the summary estimate using the "one study removed" technique (Higgins and Thompson 2002). This test allowed us to investigate sources of heterogeneity. Procedurally, this means that we ran the meta-analysis multiple times, each with a different single site removed. This procedure allowed us to detect whether any one site unduly influenced the observed effect.

We also conducted subgroup analyses based on an officer's discretion to use BWCs because the decision to activate the camera has been suggested by previous studies to affect the use of force outcomes. Table 3 reports on compliance of each site. As shown, three compliance subgroups emerged: sites in which compliance was high $(n=3)$, sites in which compliance broke down $(n=4)$, and sites in which the police maintained compliance during control conditions, but failed to follow experimental protocol during treatment shifts only $(n=3)$. Put differently, four sites gave officers discretion on when and where BWCs should be used. Three sites stripped officers of their discretion completely, but were deemed as "high compliance" sites. Three more sites adhered to the protocol for control conditions, but allowed officers discretion as to when BWCs should be used in treatment cases, including at what point during the interaction BWCs were turned on in these treatment cases.

Finally, we also estimated treatment effects on a pre-test/post-test basis in each site. Although this is viewed as weak(er) evidence (Farrington et al. 2002), the exact timing of a policy's implementation can be viewed as a natural experiment. Coupled with the multiple sites, jurisdictions, and timing of tests, the sum of this approach offers, in our view, useful evidence on potential causal effects. To assess pre-post differences we used a nonparametric analog to paired $t$-tests, the Wilcoxon signed-rank test. This test is appropriate for paired comparisons when examining nominal variables when the differences are non-normally distributed and the overall number of pairs is relatively small (McDonald 2014:186-189). We also applied bootstrapping based on 1000 bootstrap replicates. Bootstrapping (Efron 1992, Hall and Wilson 1991) does not require distributional assumptions (e.g., normally distributed errors). Bootstraps also provide more accurate inferences, particularly when the sample size is small. We then used two-tailed Monte Carlo simulations based on 10,000 sampled tables with $99 \%$ confidence intervals to further validate our results under stricter statistical conditions (Mooney 1997; see also application in Ratcliffe 2005).

\section{Results}

\section{Between-group experimental analyses}

We detected a backfiring effect of BWCs in terms of assaults on police officers in the line of duty, rather than a reduction in these incidents (Fig. 1). A total of 394 assaults per 1000 arrests occurred during 3637 treatment shifts $(\mathrm{M}=39.35, \mathrm{SD}=17.89)$ compared with 284 assaults per 1000 arrests during 3697 control shifts $(\mathrm{M}=28.38$; $\mathrm{SD}=15.99)$. 


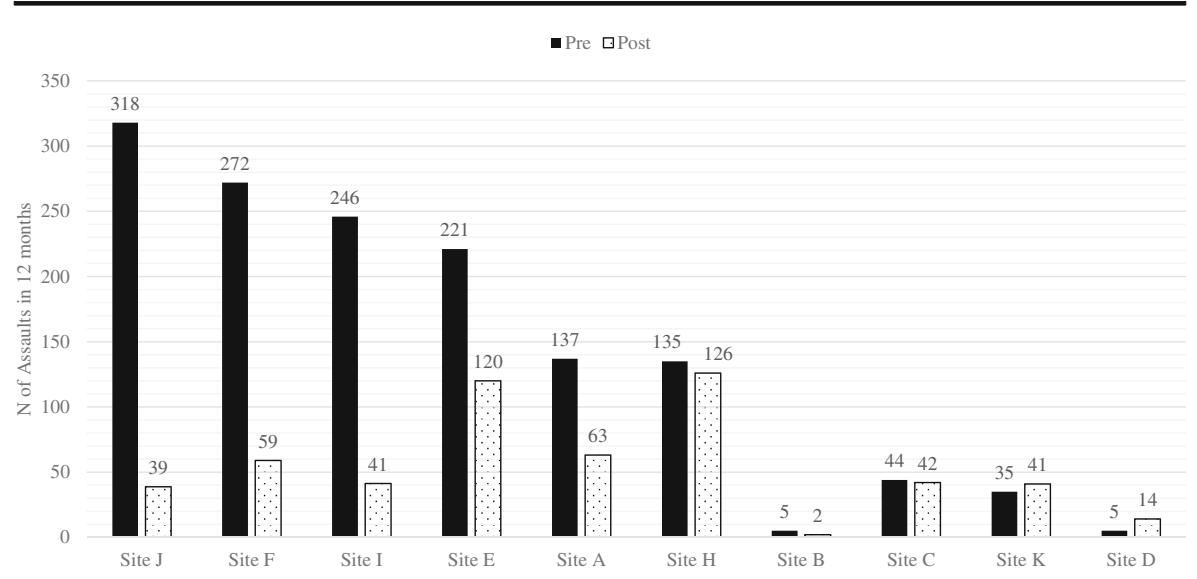

Fig. 1 Assaults on officer rates per 1000 arrests: treatment vs control conditions

Our meta-analysis of the data (see forest plot in Fig. 2) indicates that the odds of an assault against an officer during treatment conditions were between $15 \%$ to $62 \%$ greater than the odds of an assault against an officer during control conditions (average OR $=1.368 ; 95 \%$ CI 1.152, 1.624; $p<0.001)$.

Based on our meta-analysis (Fig. 2), the directionality and relative magnitude of each point estimate in eight out of ten sites was the same (i.e., the same findings emerged at each site). Two sites, however-B and D (from the same jurisdiction)deviated from the magnitude of the other sites [ $(\mathrm{OR}=43.352 ; 95 \%$ CI 2.584, 727.216; $p<0.01) ;(\mathrm{OR}=17.087 ; 95 \%$ CI 8.687, 33.608; $p<0.001)$ respectively]. These extreme estimates are not surprising given the fact that assaults against the police were 18 versus 0 and 78 versus 13 respectively, with a relatively small number of officers in these sites as well (Table 1). The extreme values in the two sites led to significant heterogeneity $\left(\mathrm{Q}=74.42 ; p<0.001 ; \mathrm{I}^{2}=79.4 \%\right)$. Removing these two sites removed the heterogeneity $\left(\mathrm{Q}=10.82 ; p<0.10 ; \mathrm{I}^{2}=35.31 \%\right)$ but also reduced the estimated effect size. Without the outlying sites, the odds of an assault against officers with

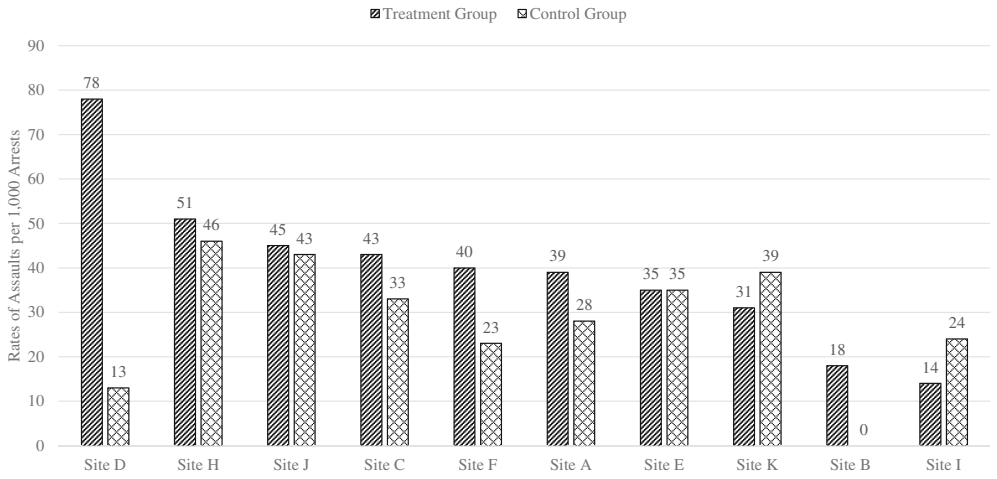

Fig. 2 Odds ratios of assaults against police officers (per 1000 arrests) 
cameras present ranged from $-5.1 \%$ to $35.4 \%$ compared to the odds under control conditions.

The "one study removed" sensitivity analysis did not change the directionality of the findings with respect to assaults against officers per 1000 arrests (Fig. 3). The point estimates of effect size ranged from a $15.0 \%$ to $48.1 \%$ increase in the odds of an assault against an officer per 1000 arrests with BWCs compared to the odds during control conditions. However, one site, a small and outlying site D, had a noticeable effect on the magnitude of the result. The removal of this study led to a relative change in the overall estimate of $15.9 \%$ (95\% CI $0.963,1.373)$.

Fig. 4 below presents the subgroup analyses based on officers' discretion. As shown, at sites where officers' discretion regarding active cameras was high $(n=4)$, the odds of assaults against officers wearing BWCs were $37 \%$ higher than the odds of assaults in control conditions $(\mathrm{OR}=1.365 ; 95 \%$ CI 1.066, 1.749). However, this backfiring treatment effect was substantially more pronounced in low-discretion sites (i.e., where officers followed the research protocol). The odds of assaults against officers under treatment conditions were $157 \%$ greater than under control conditions $(\mathrm{OR}=2.565$; $95 \%$ CI 1.792, 3.672).

\section{Odds Lower Upper \\ ratio limit limit p-Value}

$\begin{array}{lrrrr}\text { I } & 0.572 & 0.292 & 1.121 & 0.104 \\ \text { K } & 0.776 & 0.475 & 1.268 & 0.311 \\ \text { E } & 1.041 & 0.642 & 1.690 & 0.870 \\ \text { H } & 1.126 & 0.734 & 1.727 & 0.586 \\ \text { J } & 1.159 & 0.678 & 1.981 & 0.589 \\ \text { C } & 1.336 & 0.835 & 2.138 & 0.226 \\ \text { A } & 1.447 & 0.878 & 2.388 & 0.148 \\ \text { F } & 1.823 & 1.070 & 3.108 & 0.027 \\ \text { D } & 17.087 & 8.687 & 33.608 & 0.000 \\ \text { B } & 43.352 & 2.584 & 727.216 & 0.009 \\ & 1.368 & 1.152 & 1.624 & 0.000\end{array}$

0.01

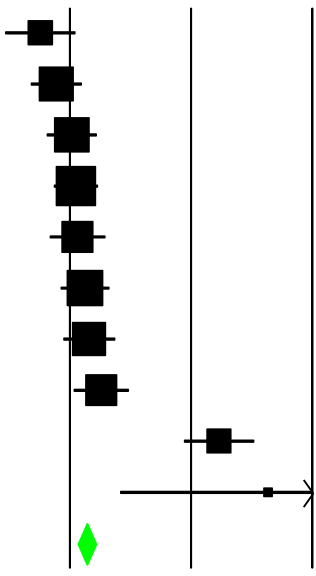

10

100 


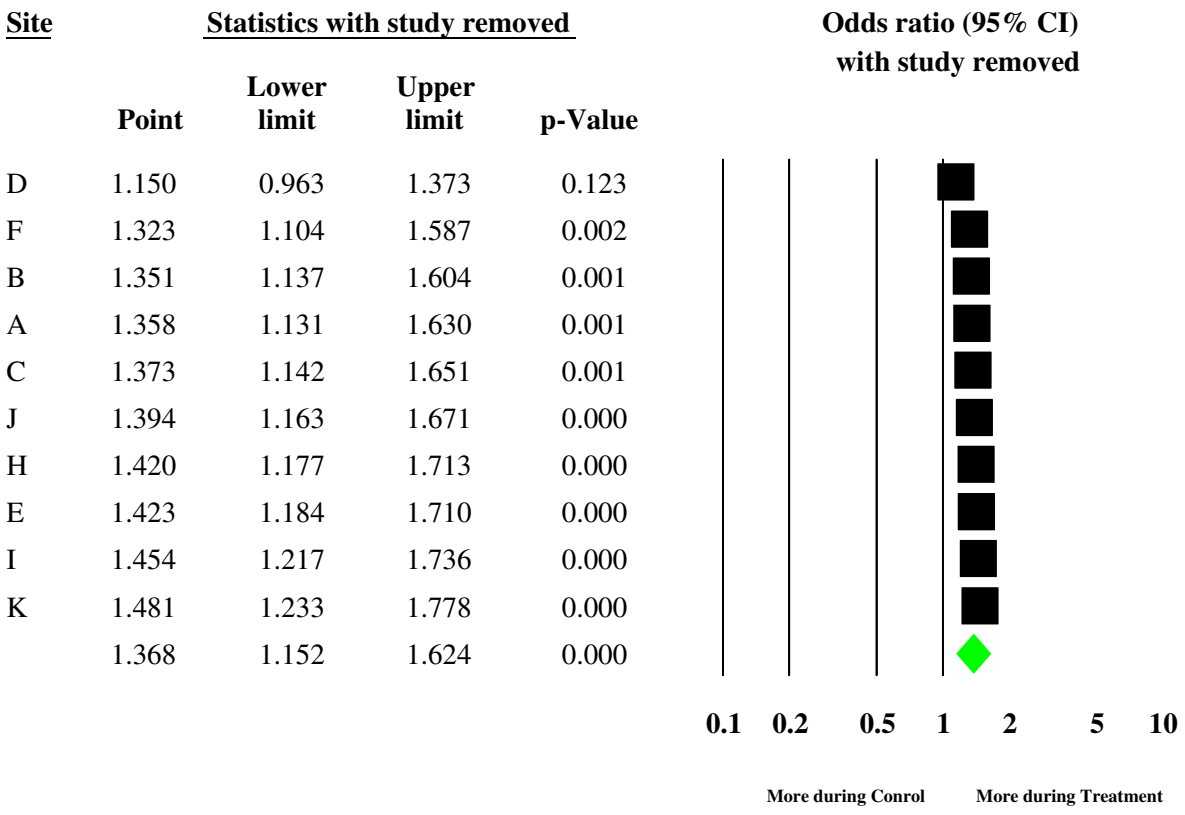

Fig. 4 Subgroup analysis: effect C on officers' discretion of BWCs based on officers' discretion

At sites that allowed officers discretion regarding when and how to turn on BWCs during treatment conditions but did not allow officers to use the devices during control conditions $(n=3)$, a nonsignificant $16 \%$ reduction in the odds of assaults compared to control conditions $(\mathrm{OR}=.835,95 \%$ CI .607, 1.149) was observed. Subgrouping the sites based on discretion removed the significant heterogeneity in this latter subgroup $(\mathrm{Q}=2.74 ; p>0.10)$ as well as in the high-discretion subgroup $(\mathrm{Q}=2.34 ; p>0.10)$ but not in the low-discretion subgroup $(\mathrm{Q}=48.28 ; p<0.01)$.

\section{Pre-post analyses}

Fig. 5 presents the counts of assaults across the ten experimental sites on a before-after basis. As shown, we counted 1418 assaults on officers in the 12 months prior to the study period and 547 assaults on officers during the study period $(M=141.8$; $S D=117.2$ ), or 1.21 assaults per officer. The number of assaults on officers decreased in the post-treatment period $(M=54.7 S D=40.4)$, or 0.42 assaults per officer. This number indicates an overall reduction of $61 \%$ in the incidence of assaults. Wilcoxon signed-rank test indicated that post-test complaints were statistically significantly lower than the pre-test complaints $(Z=-2.040 ; p=0.041)$. The Monte Carlo simulations $(99 \%$ CI $.037, .047)$ as well as the bootstrapping approach $(95 \%$ CI $28.3,154.49)$ both yielded statistically significant differences between the pre and post periods.

\section{Discussion and conclusions}

The emerging research evidence suggests that BWCs demarcate a shift in modern policing. Across thousands of police shifts in different parts of the world, over a long 


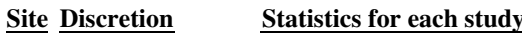

$$
\begin{aligned}
& \text { Odds } \\
& \text { ratio limit }
\end{aligned} \begin{aligned}
& \text { Upper } \\
& \text { limit }
\end{aligned}
$$

$\begin{array}{llrrrr}\text { I } & \text { During T Only } & 0.572 & 0.292 & 1.121 & 0.104 \\ \text { K } & \text { During T Only } & 0.776 & 0.475 & 1.268 & 0.311 \\ \text { J } & \text { During T Only } & 1.159 & 0.678 & 1.981 & 0.589 \\ & & 0.835 & 0.607 & 1.149 & 0.268 \\ \text { E } & \text { High } & 1.041 & 0.642 & 1.690 & 0.870 \\ \text { C } & \text { High } & 1.336 & 0.835 & 2.138 & 0.226 \\ \text { A } & \text { High } & 1.447 & 0.878 & 2.388 & 0.148 \\ \text { F } & \text { High } & 1.823 & 1.070 & 3.108 & 0.027 \\ & & 1.365 & 1.066 & 1.749 & 0.014 \\ \text { H } & \text { Low } & 1.126 & 0.734 & 1.727 & 0.586 \\ \text { D } & \text { Low } & 17.087 & 8.687 & 33.608 & 0.000 \\ \text { B } & \text { Low } & 43.352 & 2.584 & 727.216 & 0.009 \\ & & 2.565 & 1.792 & 3.672 & 0.000 \\ & & 1.368 & 1.152 & 1.624 & 0.000\end{array}$

\section{Odds ratio and 95\% CI}

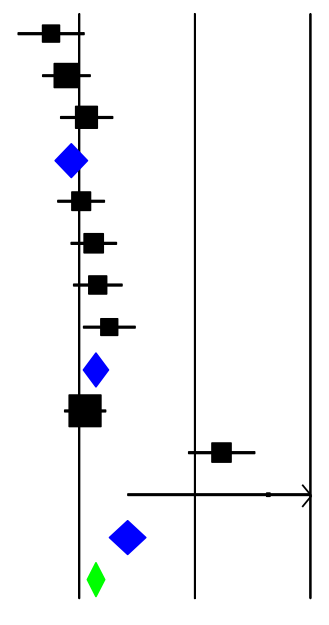

$\begin{array}{lllll}0.01 & 0.1 & 1 & 10 & 100\end{array}$

More Assaults in Control More Assaults in Treatment

Fig. 5 Assaults on officers counts: before $(n=1418)$ to after $(n=547)$ comparisons in ten experiments

period of time and with millions of residents, BWCs have been found to (a) reduce complaints against officers to nearly zero (93\% average reduction, (b) reduce the use of force by up to $50 \%$, and (c) as shown here, reduce overall assaults against officers by nearly two-thirds on the before-after comparisons across most sites (Ariel et al. 2015, 2016a, b; Jennings et al. 2015). Arrest rates have also decreased by nearly one-fifth, and even cooperation with the police has increased as a result of the use of BWCs in policing (Ariel 2016a, b). One can make the argument that no single intervention in the history of policing can claim such substantial, evidenced effects in different jurisdictions (Alpert and Dunham 1997; Bayley 1977; Emsley 2009; Newburn 2005; Reiner 2010; Sherman 1978; Walker 1977; Walker and Katz 2012).

We contextualize the present study within the framework of self-awareness of being observed, which dates back to the work of George Mean on Mind, Self and Society (1934; see also Buss 1980; Duval and Wicklund 1972; Eilan et al. 1995; Morin 2002, 2011; Wicklund 1975). By doing so, this study continues the thread of scholastic work in social psychology and the psychology of the self as a way to explain how the mere presence of a third party in our physical world causes us to modify our perceptions, our motivations, and, ultimately, our behavior. Self-awareness triggers a cognitive process of self-scrutiny and a heightened construction of one's own identity, which translates into behavior that is more compliant. In our case, we show that instead of the physical presence of a live observer, a small camera affixed to a shirt pocket causes dramatic changes.

However, there are questions about this evidence and the wider applicability of the results reported in these (and other) BWC studies. First, without a theoretical 
grounding, BWC experiments remain "black boxes" that tell us nothing about how effects are brought about. Second, to what extent can we generalize these findings beyond policing to the human condition and sociological theory more broadly? Below, we discuss such corollaries.

\section{Theoretical implications}

The effects of self-awareness on behavior provide a robust explanation for the processes behind deterrence theory as a bridge between psychology and sociology. Sociologists, and particularly criminologists, usually describe the process of deterrence from stimuli (e.g., more visible police, harsher sentences) and their aftermath ("less crime" or "more compliance"; Nagin 2013a; Nagin et al. 2015). Yet, at least in terms of a formal control apparatus, the story has mostly been rather crude: when the intervention appears, some behavioral modification is then observed (Braga et al. 2012, 2014). Precisely how the independent variables affect the dependent variables (i.e., less crime) is unclear (however, cf. Loughran et al. 2012). Self-awareness theory provides a mechanism that fits with the observed. It explains why, on whom, and under which conditions these causal links are created. It illustrates how the social world, physical stimuli, and the self interact (see Fig. 3 in Morin 2004).

Furthermore, focusing on these psychosocial processes offers an approach that is, above all, falsifiable. Deterrence, per se, is an abstract term that is difficult to quantify or measure directly (see discussion in Ariel et al. 2016a). However, more than five decades of research strongly shows that self-awareness can be experimentally induced through a clearly defined apparatus, such as an audience, recording, mirrors, or cameras (Buss 1980; Butterworth 1992, 1995; Carver and Scheier 1978; Cole and Stewart 1999; Davies 2005; Duval and Wicklund 1972; Geller and Shaver 1976; Morin 2002). Recent research even suggests that we can "view" these processes at the neurocognitive level (Cocchini et al. 2009; Dimaggio et al. 2008; Rameson and Lieberman 2009). Having the capacity to measure the treatment effect under controlled conditions is appealing to empiricists. Therefore, beyond deterrence scholars, we suspect that social control as well as rational choice theorists would find merit in the testability of these dimensions as they develop these theories in the future.

\section{"Over-deterrence"}

The evidence presented here show strong before-after effects across the various testing sites: the number of assaults on officers was significantly reduced by $61 \%$, with a reliable downward trend in eight out of ten departments. At the same time, our between-group comparisons exhibit an increase rather than a decrease in assaults when comparing treatment with control shifts. Our sensitivity analysis suggests that the between-group effect size remains broadly consistent, usually between a $35 \%$ and $48 \%$ increase in the odds of assaults against officers per 1000 arrests in treatment conditions compared to the odds in control conditions. Therefore, this multisite study provides evidence of what Merton (1936) referred to as a "perverse effect". Police departments as a whole experienced significantly fewer assaults - that is, all officers employed in these departments, with or without BWCs, experienced a lower likelihood of assault compared to the period prior to the experiment. At the same time, comparing 
treatment to control shifts actually showed that self-reported assaults were more likely when cameras were present.

Policing often requires the use of force to subdue aggressive criminals. Under these circumstances, officers must apply force not only to get the job done but also to protect themselves (see review in Friedrich 1980 as well as Sherman 1980, but see a critique in Skolnick and Fyfe 1993). However, we show that by becoming self-aware to a thirdparty observer such as BWCs, adverse results can emerge. Fig. 4 illustrates that as the degree of discretion decreases, the between-group odds of assaults against officers increases. These are police departments in which officers are fully cognizant that their interactions with the public are documented and that there is a strong likelihood of apprehension for rule violations. In the language of deterrence theory, "sanction threats" (see Ariel and Partridge 2016) were at their peak, and in the language of self-awareness theory, BWCs may have triggered a strong cognitive process of selfscrutiny (i.e., "am I doing the right thing right now?"). BWCs caused a significant reduction in the application of force (Ariel et al. 2016b). This seems like a desired consequence. At the same time, it seems that officers may have been "over-deterred" from applying force when force was in fact needed (Ariel 2017). In certain circumstances, some force is legitimate and, in fact, required. Deterrence was so strong that officers were reluctant to apply the force that was needed to stop force from being applied against them. These are undesired consequences.

We explain officers' over-deterrence in two (though not necessarily mutually exclusive) ways.

(1) Politeness as weakness. The first line of reasoning suggests that so-called "socially desirable responses" from officers are expected to include politeness and a procedural fairness approach. Some suspects may have interpreted this approach as weakness. As summarized by Kiesling (2007: 667), "Politeness is seen as powerless...men might see politeness as weakness." In other words, while following the protocol strictly (i.e., weak discretion), officers conveyed a message to offenders that they were somehow vulnerable. As a result, officers may have been more likely to be viewed by suspects as ineffective sanction threats, submissive, or feeble. Against some types of criminals, this perceived weakness translated into physical action in the form of assaults against officers.

Furthermore, it is likely that BWCs cause officers to engage verbally (and more politely) rather than resorting to "combat tactics" when, in fact, these tactics are needed. Placing ourselves in the officers' shoes for a moment, it is unsurprising that BWCs could be linked to an increased rate of assaults. As Stetser (2001: 1) notes, officers were more likely to be assaulted in certain circumstances than others - at night, when suspects were intoxicated or had mental health problems, if the officer was new to the job, and so on.

"[O]fficers were assaulted more frequently late at night and on weekends... unemployed and homeless suspects were more likely to assault...suspects who assaulted officers had usually been drinking, were under the influence of drugs, or had a mental disorder; newer officers were more likely to be injured in an assault than more experienced officers; older officers were more likely to be injured in an assault than younger officers...chemical sprays were usually effective in controlling suspects." 
Thus, responding with force is a complex and heterogeneous phenomenon. When officers with BWCs are required to subdue certain perpetrators, the cameras may cause officers to behave too softly or can convey the message that the officer would not apply force as needed. Criminals may perceive this message as a "green light" to assault officers during stand-offs without the risk of retaliation by the officer.

(2) "Skipping" stages on the force continuum. Our second interpretation of the increased ratio of assaults of officers is that the removal of discretion about turning on BWCs led officers to become over-cautious in using "aggressive voice commands." Aggressive voice commands can be effective nonphysical restraining tactics. Officers can use firm commands (i.e., request/order/threat; see Fyfe 1988; Toch 1996; Worden 1995; on the "positioning" of voice commands within the force continuum more broadly, see Table 1 in Garner et al. 1995), which often take the form of shouting, cursing, and threats. These are essential tools in the officer's toolbox against some suspects (for instance, those characterized as risk-taking, violent, and competitive - or the young male syndrome; see Wilson and Daly 1985). Nonphysical voice commands are, in fact, part and parcel of force and may be required in certain circumstances. In fact, for some forces, a "voice command" is third in a gradient continuum of seven stages, after "no force" and "police presence" (see Garner et al. 1995:158). After all, if order can be restored by using foul language rather than the use of a physical response, the former should be preferred; however, this demeanor from an officer does not look good on camera (for further on the use of profanity by officers, see Patton et al. 2017).

As argued above, BWCs cause officers to behave in socially desirable ways. Therefore, if officers are reluctant to use these aggressive voice commands because cursing is deemed inappropriate by commanding officers, BWCs may cause officers to avoid using these tactics. As a result, in situations in which some force is needed, BWCs caused officers to skip stages in the force continuum and resort to physical reactions. Thus, officers may be reluctant to use nonphysical force, when such responses are needed, given the circumstances of the interaction. Instead, the situation escalates directly from no-force response into a physical response, without the necessary aggressive voice command. This skipping leads to a violent encounter, with officer injuries. In other words, because the officers feared a response by their supervisors for applying potentially unnecessary or disproportional nonphysical force or foul language, they were induced to apply physical force and consequently placed themselves in a position in which they could be assaulted.

In summary, although psychologists have already identified negative consequences of being observed in the psychopathological sense, we show that adverse consequences can occur in the context of formal control mechanisms as well. Undesirable behavioral manifestations found in previous research on self-awareness include self-harm, avoidance, and increased emotional intensity (Baumeister 1990; Morin and Craig 2000; Moskalenko and Heine 2003; Silvia 2002; Wain 2017). However, our findings suggest that under some circumstances, self-awareness can lead to excessive self-inspection that strips power-holders of their ability to function under extreme situations. We now know 
that use of force occurs relatively early in most interactions (Willits and Makin 2017), so split-second decision-making — or what Kahneman refers to as System I Thinking (Kahneman 2011) — such as the decision to apply force in the line of duty may suffer, when an officer is aware that his actions are observed and potentially scrutinized.

\section{Unearthing the paradoxical effects}

How can we explain the overall reduction in assaults with the simultaneous increase in the odds of assaults in the treatment conditions? The most parsimonious explanation seems to be as follows: overall, officers have changed the way they behave in public. BWCs have caused an organizational learning process that Ariel et al. (2016c) referred to as "contagious accountability"; regardless of whether BWCs were actually worn, police modified their decisions through self-awareness, which translated into different behavior. At the same time, some officers may have inhibited their behavior to such an extent that they did not apply the force necessary to spare them from being injured (what we call being over-deterred). We suspect that better training and experience can potentially counter these effects, and may eventually supplant the need for BWCs in the first place as officers engage better with citizens. However, it seems that BWCs are here to stay-so it is important to carry on studying their effects, intended or otherwise, to ensure they are deployed appropriately.

Hence, while we see an overall reduction in assaults on a year-to-year basis, in most of the participating police departments the treatment conditions experienced an increase in assaults compared to control conditions, while in other departments the reversed result emerged (three departments experienced the most prominent treatment effect; however, the meta-analytic approach, coupled with the statistical sensitivity analyses, indicates that the overall effect is consistent with an increase in assaults). The practical mechanism that enables this pattern is the activation policy embraced by the police department: the more restrictive and tighter the control over officers' decisions, the more likely they will become self-aware and, by implication, less likely to react to aggressive encounters with the appropriate measures. The outcome of this self-awareness, channeled by the activation policy, is more assaults against the officers. Therefore, whether an officer is recording all of her or his contacts during the shift or only certain interactions with the public, could have profound differences on whether and how the officer changes behavior. Response to being recorded for all interactions could be vastly different than a response when only being recorded during an encounter the officer elects to record. This implies that departments should assist frontline officers in overcoming issues associated with the perceived politeness as weakness as well as the skipping through the stages of the force continuum, as we alluded to earlier, when using BWCs.

\section{A final word about "assaults" against police officers}

Different jurisdictions around the globe define "assaults against the police" in different ways. One prominent distinction is between verbal assaults and physical assaults. Verbal abuse can be considered a crime, depending on how vitriolic it is, to what extent it interferes with a police officer in her or his duties, and the circumstances of the case. Physical violence often falls under battery charges, hence the charge of assault and battery in many jurisdictions. However, in many jurisdictions across the United 
States, "contempt of a cop", that is, a nonthreatening, nonphysical assault and disrespect of a police officer, is usually not deemed a criminal offense, as such discourse is often protected under a constitutional guard of freedom of speech. ${ }^{6}$ On the other hand, in places like the United Kingdom and other countries, verbal transgressions may be considered notifiable offenses, when they cause "harassment, alarm or distress" of the officer. $^{7}$

In our experiments, we included both verbal as well as physical assaults of officers. We had no way to separate the type of assault, as we were limited by the provisions of our data-sharing agreements with the participating police departments. This caveat must be recognized, as we consider the practical implications of the study. Perhaps, for example, the increase in treatment group compared to control group is the result of an increase in primarily verbal incidents rather than physical assault (i.e., upon being notified that they are on camera, citizens try to taunt officers into misconduct by verbally assaulting them, knowing that officers cannot do much about it). On the other hand, we suspect that at least some of the assaults against of the officers were physical; however, we cannot determine how many. Consequently, it can be the case that officers wearing BWCs were able to de-escalate situations where often verbal abuse is common, but such cooling down while using BWCS is not feasible for situations involving physical abuse of officers. We cannot tell.

As our data do not allow us to make such inferences, we call instead for other scholars to pay a closer attention to the distinction between types of assaults than we could, when designing trials on BWCs. At the same time, we note that both verbal and nonverbal aggression at the workplace are considered as a serious concern. Workplace violence has been found to correlate significantly with psychological strain, burn-out fatigue, perceptions of danger, anxiety, and potentially PTSD (see Alkus and Padesky 1983; Anshel 2000; Burke and Deszca 1986; MacDonald et al. 2003; Robinson et al. 1997). Even if the effect concentrates on nonverbal aggression, a backfiring effect of BWCs on police officers' wellbeing can lead to both personal as well as organizational adverse consequences, a perverse consequence we ought to minimize.

\section{Compliance with ethical standards}

Conflict of interest The authors declare no conflict of interests.

Open Access This article is distributed under the terms of the Creative Commons Attribution 4.0 International License (http://creativecommons.org/licenses/by/4.0/), which permits unrestricted use, distribution, and reproduction in any medium, provided you give appropriate credit to the original author(s) and the source, provide a link to the Creative Commons license, and indicate if changes were made.

\footnotetext{
${ }^{6}$ City of Houston vs Hill, 482 U.S. 451

7 Southard vs DPP [2006] EWHC 3449. The UK Section 5 of the Public Order Act 1986 makes the following provision: "(1) A person is guilty of an offense if he; a) uses threatening, abusive or insulting words or behavior, or disorderly behavior, or b) displays any writing, sign or other visible representation which is threatening, abusive or insulting, within the hearing or sight of a person likely to be caused harassment, alarm or distress thereby".
} 


\section{References}

Alkus, S., \& Padesky, C. (1983). Special problems of police officers: stress-related issues and interventions. The Counseling Psychologist, 11(2), 55-64.

Alpert, G. P., \& Dunham, R. G. (1997). The force factor: measuring police use of force relative to suspect resistance. Washington, DC: Police Executive Research Forum.

Alpert, G. P., \& MacDonald, J. M. (2001). Police use of force: an analysis of organizational characteristics. Justice Quarterly, 18(2), 393-409.

Alpert, G., Kenney, D., Dunham, R., \& Smith, W. (2000). Police pursuits: what we know. Washington, DC: Police Executive Research Forum.

Anshel, M. H. (2000). A conceptual model and implications for coping with stressful events in police work. Criminal Justice and Behavior, 27(3), 375-400.

Ariel, B. (2016). The puzzle of police body cams. IEEE Spectrum, 53(7), 32-37

Ariel, B. (2016a). The effect of police body-worn videos on use of force, complaints and arrests in large police departments. Journal of Criminal Law and Criminology, 106(4), 729-768.

Ariel, B. (2016b). Increasing cooperation with the police using body worn cameras. Police quarterly, 19(3), 326-362.

Ariel, B., Sutherland, A., Henstock, D., Young, J., Drover, P., Sykes, J., \& Henderson, R. (2016). Wearing body cameras increases assaults against officers and does not reduce police use of force: Results from a global multi-site experiment. European Journal of Criminology, 13(6), 744-755.

Ariel, B., \& Partridge, H. (2016). Predictable policing: measuring the crime control benefits of hotspots policing at bus stops. Journal of Quantitative Criminology. https://doi.org/10.1007/s10940-016-9312-y125 .

Ariel, B., Vila, J., \& Sherman, L. (2012). Random assignment without tears: how to stop worrying and love the Cambridge randomizer. Journal of Experimental Criminology, 8(2), 193-208.

Ariel, B., Farrar, W. A., \& Sutherland, A. (2015). The effect of police body-worn cameras on use of force and citizens' complaints against the police: a randomized controlled trial. Journal of Quantitative Criminology $31,509-535$.

Ariel, B., Weinborn, C., \& Sherman, L. W. (2016a). "Soft" policing at hot spots-Do police community support officers work? A randomized controlled trial. Journal of Experimental Criminology 12(3), 277317

Ariel, B., Sutherland, A., Henstock, D., Young, J., Drover, P., Sykes, J., Megicks, S., \& Henderson, R. (2016b). Report: increases in police use of force in the presence of body-worn cameras are driven by officer discretion: a protocol-based subgroup analysis of ten randomized experiments. Journal of Experimental Criminology, 12(3), 453-463.

Ariel, B., Sutherland, A., Henstock, D., Young, J., \& Sosinski, G. (2017). The deterrence spectrum: Explaining why police body-worn cameras 'work'or 'backfire'in aggressive police-public encounters. Policing: A Journal of Policy and Practice, paw051.

Ariel, B., Sutherland, A., Henstock, D., Young, J., Drover, P., Sykes, J., Megicks, S., \& Henderson, R. (2017). "Contagious accountability" a global multisite randomized controlled trial on the effect of police bodyworn cameras on citizens' complaints against the police. Criminal Justice and Behavior 44(2), 293-316

Bandura, A. (1978). The self system in reciprocal determinism. American Psychologist, 33(4), 344.

Barclay, P. (2004). Trustworthiness and competitive altruism can also solve the "tragedy of the commons". Evolution and Human Behavior, 25(4), 209-220.

Bateson, M., Nettle, D., \& Roberts, G. (2006). Cues of being watched enhance cooperation in a real-world setting. Biology Letters, 2(3), 412-414.

Baumeister, R. F. (1990). Suicide as escape from self. Psychological Review, 97(1), 90.

Bayley, D. H. (1977). Police and society. Beverly Hills: Sage Publications.

Berk, R., \& MacDonald, J. (2010). Policing the homeless. Criminology \& Public Policy, 9(4), 813-840.

Bierie, D. M. (2015). Assault of police. Crime \& Delinquency 63(8):899-925. https://doi.org/10.1177 /0011128715574977

Blau, J. R., \& Blau, P. M. (1982). The cost of inequality: metropolitan structure and violent crime. American Sociological Review 47(1), 114-129.

Bottoms, A., \& Tankebe, J. (2012). Beyond procedural justice: a dialogic approach to legitimacy in criminal justice. The Journal of Criminal Law and Criminology, 102, 119.

Boyd, R., Gintis, H., \& Bowles, S. (2010). Coordinated punishment of defectors sustains cooperation and can proliferate when rare. Science, 328(5978), 617-620. 
Braga, A., Papachristos, A., \& Hureau, D. (2012). Hot spots policing effects on crime. Campbell Systematic Reviews, 8(8), 1-96.

Braga, A. A., Papachristos, A. V., \& Hureau, D. M. (2014). The effects of hot spots policing on crime: An updated systematic review and meta-analysis. Justice Quarterly, 31(4), 633-663.

Brandl, S. G. (1996). In the line of duty: A descriptive analysis of police assaults and accidents. Journal of Criminal Justice, 24(3), 255-264.

Brandl, S. G., \& Stroshine, M. S. (2003). Toward an understanding of the physical hazards of police work. Police Quarterly, 6(2), 172-191.

Brown, J. M. (1998). Aspects of discriminatory treatment of women police officers serving in forces in England and Wales. British Journal of Criminology, 38(2), 265-282.

Burke, R. J., \& Deszca, E. (1986). Correlates of psychological burnout phases among police officers. Human Relations, 39(6), 487-501.

Burnham, T. C., \& Johnson, D. D. P. (2005). The biological and evolutionary logic of human cooperation. Analyse \& Kritik, 27(1), 113-135.

Bushway, S., \& Reuter, P. (2008). Economists' contribution to the study of crime and the criminal justice system. Crime and Justice, 37(1), 389-451.

Buss, A. H. (1980). Self-consciousness and social anxiety. San Francisco: Freeman.

Butterworth, G. (1992). Origins of self-perception in infancy.Psychological Inquiry, 3(2), 103-111.

Butterworth, G. (1995). An ecological perspective on the origins of self. In J.L. Bermudez, A. Marcel, \& N. Eilan (Eds.)The body and the self (pp. 87-107). Cambridge, MA: MIT Bradford Press

Carver, C. S., \& Scheier, M. F. (1978). Self-focusing effects of dispositional self-consciousness, mirror presence, and audience presence. Journal of Personality and Social Psychology, 36(3), 324.

Carver, C. S. \& Scheier, M. F. (2004). Self-regulation of action and affect. In K.D. Vohs \& R. F. Baumeister (Eds.), Handbook of self-regulation: research, theory, and applications(pp. 13-39). New York, NY: Guilford

Chartrand, T. L., \& Bargh, J. A. (1999). The chameleon effect: the perception-behavior link and social interaction. Journal of Personality and Social Psychology, 76(6), 893.

Cocchini, G., Beschin, N., Cameron, A., Fotopoulou, A., \& Sala, S. D. (2009). Anosognosia for motor impairment following left brain damage. Neuropsychology, 23(2), 223.

Cohen, J. (1988). Statistical power analysis: A computer program. Abingdon, UK: Routledge.

Cole, P., \& Stewart, N. (1999). In search of situational effects in outdoor recreation: different methods, different results. Leisure Sciences, 21(4), 269-286.

Cox, D. R. (1958), Planning of Experiments, New York: Wiley

Cubitt, T. I. C., Lesic, R., Myers, G. L., \& Corry, R. (2017). Body-worn video: a systematic review of literature. Australian \& New Zealand Journal of Criminology 50(3), 379-396

Davies, M. F. (2005). Mirror and camera self-focusing effects on complexity of private and public aspects of identity. Perceptual and Motor Skills, 100(3), 895-898.

Davis, D., \& Brock, T. C. (1975). Use of first person pronouns as a function of increased objective selfawareness and performance feedback. Journal of Experimental Social Psychology, 11(4), 381-388.

Davis, M. H., \& Franzoi, S. L. (1991). Stability and change in adolescent self-consciousness and empathy. Journal of Research in Personality, 25(1), 70-87.

de Brito, C., \& Ariel, B. (2017). Does Tracking and Feedback Boost Patrol Time in Hot Spots? Two Tests. Cambridge Journal of Evidence-Based Policing, 1(4), 244-262.

Dimaggio, G., Lysaker, P. H., Carcione, A., Nicolò, G., \& Semerari, A. (2008). Know yourself and you shall know the other... to a certain extent: Multiple paths of influence of self-reflection on mindreading. Consciousness and Cognition, 17(3), 778-789.

Drover, P. \& Ariel, B. (2015). Leading an experiment in police body-worn video cameras. International Criminal Justice Review 25(1), 80-97

Duval, S. \& Wicklund R. A. (1972). A theory of objective self awareness. New York: Academic Press

Dzieweczynski, T. L., Eklund, A. C., \& Rowland, W. J. (2006). Male 11-Ketotestosterone levels change as a result of being watched in Siamese fighting fish, Betta Splendens. General and Comparative Endocrinology, 147(2), 184-189.

Efron, B. (1992). Bootstrap methods: another look at the jackknife. In S. Kotz, N.L. Johnson (Eds.), Breakthroughs in statistics(pp. 569-593). New York: Springer.

Eilan, N., Marcel, A., \& Bermùdez, J. L. (1995). Self-consciousness and the body: an interdisciplinary introduction. In J.L. Bermudez, A. Marcel, \& N. Eilan (Eds.)The body and the self (pp. 1-21). Cambridge, MA: MIT Bradford Press

Ellis, T., Jenkins, C., \& Smith, P. (2015). Evaluation of the introduction of personal issue body worn video cameras (Operation Hyperion) on the Isle of Wight: final report to Hampshire Constabulary 
Emsley, Clive. 2009. The great British bobby: a history of British policing from the 18th century to the present. London: Quercus.

Farrington, D. P., Gottfredson, D. C., Sherman, L. W., \& Welsh, B. C. (2002). The Maryland scientific methods scale. In L. Sherman, D. Farrington, B. Welsh, \& D. MacKenzie (Eds.), Evidence-based crime prevention (pp. 13-21). Routledge: London and New York.

Friedrich, R. J. (1980). Police use of force: Individuals, situations, and organizations. The Annals of the American Academy of Political and Social Science, 452(1), 82-97.

Froming, W. J., Rex Walker, G., \& Lopyan, K. J. (1982). Public and private self-awareness: When personal attitudes conflict with societal expectations. Journal of Experimental Social Psychology, 18(5), 476-487.

Fryer, R. G. Jr. (2016). An empirical analysis of racial differences in police use of force. NEBR Working Paper 22399. Cambridge, MA: National Bureau of Economic Research.

Fyfe, J. J. (1988). Police use of deadly force: research and reform. Justice Quarterly, 5(2), 165-205.

Galliher, J. F. (1971). Explanations of police behavior: a critical review and analysis. The Sociological Quarterly, 12(3), 308-318.

Garner, J. H., Schade, T., Hepburn, J., \& Buchanan, J. (1995). Measuring the continuum of force used by and against the police. Criminal Justice Review, 20(2), 146-168.

Geller, V., \& Shaver, P. (1976). Cognitive consequences of self-awareness. Journal of Experimental Social Psychology, 12(1), 99-108.

Gervais, W. M., \& Norenzayan, A. (2012). Like a camera in the sky? Thinking about god increases public selfawareness and socially desirable responding. Journal of Experimental Social Psychology, 48(1), 298-302.

Goodall, M. (2007). Guidance for the police use of body-worn video devices. London: Home Office

Haley, K. J., \& Fessler, D. M. T. (2005). Nobody's watching?: subtle cues affect generosity in an anonymous economic game. Evolution and Human Behavior, 26(3), 245-256.

Hall, P., \& Wilson, S. R. (1991). Two guidelines for bootstrap hypothesis testing. Biometrics, 47, 757-762.

Hedberg, E. C., Katz, C. M., \& Choate, D. E. (2017). Body-worn cameras and citizen interactions with police officers: estimating plausible effects given varying compliance levels. Justice Quarterly, 34(4), 627-651.

Heine, S. J., Takemoto, T., Moskalenko, S., Lasaleta, J., \& Henrich, J. (2008). Mirrors in the head: cultural variation in objective self-awareness. Personality and Social Psychology Bulletin, 34(7), 879-887.

Henriquez, M. (1999). The Iacp National Police use-of-force database project. Police Chief, 66, 154-159.

Henstock, D., \& Ariel, B. (2017). Testing the effects of police body-worn cameras on use of force during arrests: A randomised controlled trial in a large British police force. European Journal of Criminology, 1477370816686120.

Herbert, S. (1998). Police subculture reconsidered. Criminology, 36, 343.

Higgins, J. P. T., \& Thompson, S. G. (2002). Quantifying heterogeneity in a meta-analysis. Statistics in Medicine, 21(11), 1539-1558.

Jennings, W. G., Fridell, L. A., \& Lynch, M. D. (2014). Cops and cameras: Officer perceptions of the use of body-worn cameras in law enforcement. Journal of Criminal Justice, 42(6), 549-556.

Jennings, W. G., Lynch, M. D., \& Fridell, L. A. (2015). Evaluating the impact of police officer body-worn cameras (Bwcs) on response-to-resistance and serious external complaints: evidence from the Orlando police department (Opd) experience utilizing a randomized controlled experiment. Journal of Criminal Justice, 43(6), 480-486.

Jervis, R. (1989). Rational deterrence: Theory and evidence. World Politics, 41(02), 183-207.

Jones, E. E. \& Nisbett R.E. (1971). The actor and the observer: divergent perceptions of the causes of behavior. New York: General Learning Press

Kahneman, D. (2011). Thinking, fast and slow. New York: Macmillan.

Kaminski, R. J. (2004). The murder of police officers. New York: LFB Scholarly Pub LLC.

Kaminski, R. J., \& Sorensen, D. W. M. (1995). A multivariate analysis of individual, situational and environmental factors associated with police assault injuries. American Journal of Police, 14(3/4), 3-48.

Kaminski, R. J., Digiovanni, C., \& Downs, R. (2004). The use of force between the police and persons with impaired judgment. Police Quarterly, 7(3), 311-338.

Kanfer, F. H. (1977). The many faces of self-control, or behavior modification changes its focus. In R. B. Stuart (Ed.) Behavioral self-management: Strategies, techniques, and outcomes(pp. 1-48). New York: Brunner/Mazel.

Katz, C. M., Choate, D. E., Ready, J. R., Nuňo, L., Kurtenbach, C. M., \& Kevin, S. (2014). Evaluating the impact of officer worn body cameras in the Phoenix police department. Retrieved from https://publicservice.asu.edu/sites/default/files/ppd_spi_feb_20_2015_final.pdf

Kiesling, S. (2007). Men, masculinities, and language. Language and Linguistics Compass, 1(6), 653-673.

Lipsey, M. W., \& Wilson, D. B. (2001). Practical meta-analysis, Vol (p. 49). Thousand Oaks, CA: Sage Publications. 
Lochner, T. (2003). Overdeterrence, underdeterrence, and a (half-hearted) call for a scarlet letter approach to deterring campaign finance violations. Election Law Journal, 2(1), 23-41.

Loughran, T. A., Pogarsky, G., Piquero, A. R., \& Paternoster, R. (2012). Re-examining the functional form of the certainty effect in deterrence theory. Justice Quarterly, 29(5), 712-741.

Lum, C., Koper, C. S., Merola, L. M., Scherer, A., Reioux, A. (2015). Existing and ongoing body worn camera research: Knowledge gaps and opportunities. Report for the Laura and John Arnold Foundation. Center for Evidence-Based Crime Policy, George Mason University.

MacDonald, H. A., Colotla, V., Flamer, S., \& Karlinsky, H. (2003). Posttraumatic stress disorder (PTSD) in the workplace: A descriptive study of workers experiencing PTSD resulting from work injury. Journal of Occupational Rehabilitation, 13(2), 63-77.

MacKenzie, D. L., Umamaaheswar, J., \& Lin, L. C. (2013). Multisite randomized trials in criminology. In B. C. Welsh, A. A. Braga, G. J. Bruinsma (Eds.), Experimental criminology: Prospects for advancing science and public policy (pp. 163-193). New York, NY: Cambridge University Press

Margarita, M. (1980). Killing the police: myths and motives. The Annals of the American Academy of Political and Social Science, 452(1), 63-71.

Maskaly, J., \& Donner, C. M. (2015). A theoretical integration of social learning theory with terror management theory: Towards an explanation of police shootings of unarmed suspects. American Journal of Criminal Justice, 40(2), 205-224.

Maskaly, J., Donner, C., Jennings, W., Ariel, B., and Sutherland, A (2017). The effects of body-worn cameras (BWCs) on police and citizen outcomes: A state-of-the-art review. Policing: An International Journal of Police Strategies \& Management. 40(4), 672-688, https://doi.org/10.1108/PIJPSM-03-2017-0032

McCord, J., \& Conway, K. P. (2002). Patterns of juvenile delinquency and co-offending. Crime and social organization, $10,15$.

McDonald, J.H. 2014. Handbook of Biological Statistics (3rd ed.). Sparky House Publishing, Baltimore, Maryland.

Mead, G. H. (1934). Mind, self and society, Vol. 111. Chicago: University of Chicago Press.

Meyer, G. (1992). Nonlethal weapons vs. conventional police tactics: assessing injuries and liabilities. The Police Chief, 59, 10-17.

Milinski, M., Semmann, D., \& Krambeck, H. (2002). Donors to charity gain in both indirect reciprocity and political reputation. Proceedings of the Royal Society of London B: Biological Sciences, 269(1494), 881883.

Mooney, C. Z. (1997). Monte Carlo simulation. Thousand Oaks: Sage Publications.

Morin, A. (2002). Self-awareness review part 1: do you "self-reflect" or "self-ruminate"? Science \& Consciousness Review, 1.

Morin, A. (2004). A neurocognitive and socioecological model of self-awareness. Genetic, Social, and General Psychology Monographs, 130(3), 197-224.

Morin, A. (2005). Possible links between self-awareness and inner speech theoretical background, underlying mechanisms, and empirical evidence. Journal of Consciousness Studies, 12(4-5), 115-134.

Morin, A. (2011). Self-awareness part 1: Definition, measures, effects, functions, and antecedents. Social and Personality Psychology Compass, 5(10), 807-823.

Morin, A., \& Craig, L. (2000). Self-awareness, self-esteem, and alcohol use in famous and relatively wellknown individuals. Current Research in Social Psychology, 5(16), 236-253.

Morrow, W. J., Katz, C. M., \& Choate, D. E. (2016). Assessing the impact of police body-worn cameras on arresting, prosecuting, and convicting suspects of intimate partner violence. Police Quarterly, 1098611116652850.

Moskalenko, S., \& Heine, S. J. (2003). Watching your troubles away: television viewing as a stimulus for subjective self-awareness. Personality and Social Psychology Bulletin, 29(1), 76-85.

Munger, K., \& Harris, S. J. (1989). Effects of an observer on hand washing in a public restroom. Perceptual and Motor Skills, 69(3), 733-734.

Nagin, D. S. (2013a). Deterrence in the twenty-first century. Crime and Justice, 42(1), 199-263.

Nagin, D. S. (2013b). Deterrence: a review of the evidence by a criminologist for economists. Annu. Rev. Econ., 5(1), 83-105.

Nagin, D. S., Solow, R. M., \& Lum, C. (2015). Deterrence, criminal opportunities, and police. Criminology, 53(1), 74-100.

Newburn, T. (2005). Handbook of policing. Portland, OR: Willan.

Northover, S. B., Pedersen, W. C., Cohen, A. B., \& Andrews, P. W. (2017). Artificial surveillance cues do not increase generosity: two meta-analyses. Evolution and Human Behavior, 38(1), 144-153.

Obama, B. (2016). The President's Role in Advancing Criminal Justice Reform. Harv. L. Rev., 130, 811.

Ojedokun, U. A. (2014). Contributing factors to police homicide in Nigeria. The Police Journal, 87(1), 41-48. 
Owens, C., Mann, D. and McKenna, R. (2014). The Essex Body Worn Video Trial: the impact of body worn video on criminal justice outcomes of domestic abuse incidents. College of Policing, UK

Pang, M.-S., \& Pavlou, P. A. (2016). Armed with technology: the effects on fatal shootings of civilians by the police. In Available at SSRN.

Paternoster, R. (2010). How much do we really know about criminal deterrence? The Journal of Criminal Law and Criminology, 100(3), 765-824.

Patton, C. L., Asken, M., Fremouw, W. J., \& Bemis, R. (2017). The influence of police profanity on public perception of excessive force. Journal of Police and Criminal Psychology. https://doi.org/10.1007 /s11896-017-9226-0.

Paulhus, D. L. (1988). Balanced Inventory of Desirable Responding (BIDR). Acceptance and Commitment Therapy. Measures Package 41.

Pfattheicher, S. (2015). A regulatory focus perspective on reputational concerns: the impact of preventionfocused self-regulation. Motivation and Emotion, 39(6), 932-942.

Pfattheicher, S., \& Keller, J. (2015). The watching eyes phenomenon: The role of a sense of being seen and public self-awareness. European Journal of Social Psychology, 45(5), 560-566.

Pratt, T. C., Cullen, F. T., Blevins, K. R., Daigle, L. E., \& Madensen, T. D. (2006). The empirical status of deterrence theory: a meta-analysis. Taking stock: The status of criminological theory, 15, 367-396.

Rameson, L. T., \& Lieberman, M. D. (2009). Empathy: a social cognitive neuroscience approach. Social and Personality Psychology Compass, 3(1), 94-110.

Ratcliffe, J. H. (2005). Detecting spatial movement of intra-region crime patterns over time. Journal of Quantitative Criminology, 21(1), 103-123.

Ready, J. T., \& Young, J. T. N. (2015). The impact of on-officer video cameras on police-citizen contacts: findings from a controlled experiment in mesa, Az. Journal of Experimental Criminology, 11(3), 445458.

Reiner, R. (2010). The Politics of the Police. Oxford: Oxford University Press.

Robinson, H. M., Sigman, M. R., \& Wilson, J. P. (1997). Duty-related stressors and PTSD symptoms in suburban police officers. Psychological Reports, 81(3), 835-845.

Roy, A. (2014). On-officer video cameras: Examining the effects of police department policy and assignment on camera use and activation. ( $\mathrm{PhD}$ dissertation, Arizona State University).

Sherman, L. W. (1978). Scandal and reform: Controlling police corruption. Berkeley, CA: Univ of California Press.

Sherman, L. W. (1980). Causes of police behavior: the current state of quantitative research. Journal of Research in Crime and Delinquency, 17(1), 69-100.

Silvia, P. J. (2002). Self-awareness and the regulation of emotional intensity. Self and Identity, 1(1), 3-10.

Skolnick, J. H. (2008). Enduring issues of police culture and demographics. Policing \& society, 18(1), 35-45.

Skolnick, J. H., \& Fyfe, J. J. (1993). Above the law: Police and the excessive use of force. New York: Free Press.

Slothower, M., Sherman, L. W., \& Neyroud, P. (2015). Tracking quality of police actions in a victim contact program a case study of training, tracking, and feedback (TTF) in evidence-based policing. International Criminal Justice Review 25(1), 98-116

Smith, M. R., \& Petrocelli, M. (2002). The effectiveness of force used by police in making arrests. Police Practice and Research, 3(3), 201-215.

Smith, W. A., Allen, W. R., \& Danley, L. L. (2007). "Assume the position... You fit the description" psychosocial experiences and racial battle fatigue among African-American male college students. American Behavioral Scientist, 51(4), 551-578.

Sproull, L., Subramani, M., Kiesler, S., Walker, J. H., \& Waters, K. (1996). When the interface is a face. Human-Computer Interaction, 11(2), 97-124.

Stetser, M. (2001). The use of force in police control of violence: Incidents resulting in assaults on officers. New York: LFB Scholarly.

Sunstein, Cass R. (2014). Nudges vs. Shoves. In Forthcoming Harvard Law Review Forum. http://dx.doi.org/ $10.2139 /$ ssrn. 2390120

Sunstein, C., \& Thaler, R. (2008). Nudge. New Haven, CT: Yale University Press. Ten Examples of Early Tortoise-Shell Inscriptions. Harvard Journal of Asiatic Studies, 11, 1-2.

Sutherland, A. and Ariel, B. (2016) Body worn cameras: technology meets complexity. International Council of Police Representative Associations (ICPRA), December 2016. http://www.icpra. org/sites/default/files/icpra_enews_issue_4_2016.pdf

Sutherland, A., Ariel, B., Farrar, W., \& De Anda, R. (2017). Post-experimental follow-ups-Fade-out versus persistence effects: The Rialto police body-worn camera experiment four years on. Journal of Criminal Justice, 53, 110-116. 
Tankebe, J. and Ariel, B. (2016). Cynicism Towards Change: The Case of Body-Worn Cameras Among Police Officers (October 10, 2016). Hebrew University of Jerusalem Legal Research Paper No. 16-42. Available at SSRN: https://ssrn.com/abstract=2850743

Taylor, E. (2016). Lights, camera, redaction... Police body-worn cameras: autonomy, discretion and accountability. Surveillance \& Society, 14(1), 128.

Terrill, W. (2001). Police coercion: application of the force continuum. New York, NY: LFB Scholarly Publishing LLC.

Tibbetts, S. G. (2013). Traits and states of self-conscious emotions in criminal decision making. In J.L. VanGelder, H. Elffers, D. Reynaud, D. Nagin (Eds.)Affect and cognition in criminal decision making(pp. 113-125). London: Routledge.

Toch, H. (1996). The violence-prone police officer. In W.A.Geller, H. Toch (Eds.) Police violence: Understanding and controlling police abuse of force (pp. 94-112). New Haven, CT: Yale University Press

Tonry, M. (2008). Learning from the limitations of deterrence research. Crime and Justice, 37(1), $279-311$.

Tyler, T. R. (1990). Why people obey the law: Procedural justice, legitimacy, and compliance. New Haven: Yale University Press.

Tyler, T. R., \& Lind, E. A. (1992). A relational model of authority in groups. Advances in Experimental Social Psychology, 25, 115-191.

Von Hirsch, A., Bottoms, A.E., Burney, E., Wikstrom. P. O. (1999). Criminal deterrence and sentence severity: an analysis of recent research: Oxford: Hart.

Waddington, P. A. J. (1999). Police (canteen) sub-culture. an appreciation. British Journal of Criminology, 39(2), 287-309.

Wain, N., Ariel, B., \& Tankebe, J. (2017). The collateral consequences of GPSLED supervision in hot spots policing. Police Practice and Research, 18(4), 376-390.

Walker, S. (1977). A critical history of police reform. Lexington: Lexington Books.

Walker, S., \& Katz, C. M. (2012). Police in America. New York: McGraw-Hill.

Wedekind, C., \& Braithwaite, V. A. (2002). The long-term benefits of human generosity in indirect reciprocity. Current Biology, 12(12), 1012-1015.

Weisburd, D., \& Taxman, F. S. (2000). Developing a multicenter randomized trial in criminology: The case of HIDTA. Journal of Quantitative Criminology, 16(3), 315-340.

Whichard, C., \& Felson, R. B. (2016). Are suspects who resist arrest defiant, desperate, or disoriented? Journal of Research in Crime and Delinquency, 53(4), 564-591.

White, M. D. (2014). Police officer body-worn cameras: Assessing the evidence. Washington, DC: Office of Community Oriented Policing Services.

White, M., \& Coldren J. (2017). Body-worn police cameras: Separating fact from fiction. International City/ county management association. Available at http://icma.org/en/Article/107941/BodyWorn_Police_ Cameras_Separating Fact from_Fiction (retrieved 18 April 2017).

Wicklund, R. A. (1975). Objective self-awareness. Advances in Experimental Social Psychology, 8, $233-275$.

Wikström, P.-O. H., \& Treiber, K. (2007). The role of self-control in crime causation beyond Gottfredson and Hirschi's general theory of crime. European Journal of Criminology, 4(2), 237-264.

Willits, D. W., \& Makin, D. A. (2017). Show me what happened: analyzing use of force through analysis of body-worn camera footage. Journal of Research in Crime and Delinquency. https://doi.org/10.1177/ 0022427817701257.

Wilson, J. Q. (1968). Varieties of police behavior: The management of law and order in eight communities. Cambridge, MA: Harvard University Press.

Wilson, M., \& Daly, M. (1985). Competitiveness, risk taking, and violence: The young male syndrome. Ethology and Sociobiology, 6(1), 59-73.

Worden, R. (1995). The 'causes' of police brutality: theory and evidence on police use of force. In W. A. Geller, H. Toch (Eds.) And justice for all: Understanding and controlling police abuse of force (pp. 31-60). Washington, DC : Police Executive Research Forum

Young, J. T. N., \& Ready, J. T. (2016). A longitudinal analysis of the relationship between administrative policy, technological preferences, and body-worn camera activation among police officers. Policing: A Journal of Policy and Practice. https://doi.org/10.1093/police/paw005

Dr. Barak Ariel is a Senior Lecturer at the Institute of Criminology, Faculty of Law, at the Hebrew University and a Lecturer in Experimental Criminology at the Institute of Criminology, University of Cambridge.

Dr. Alex Sutherland is a research leader at RAND Europe. 
Darren Henstock was an Inspector in West Midlands Police at the time of the study, and is a graduate of the Police Executive Programme at the University of Cambridge.

Joshua Young was a senior officer at the Ventura, CA Police Department at the time of the study. He is a Fellow at the Police Foundation, LEADS Scholar, and co-founder of the American Society of Evidence-Based Policing. He is a graduate of the Police Executive Programme at the University of Cambridge.

Paul Drover is a Detective Superintendent in West Midlands Police and a graduate of the Police Executive Programme at the University of Cambridge.

Jayne Sykes heads the performance and intelligence analysis team at West Yorkshire police, and is a graduate of the Police Executive Programme at the University of Cambridge.

Simon Megicks is an Assistant Chief Constable in Hertfordshire Constabulary and a graduate of the Police Executive Programme at the University of Cambridge.

Ryan Henderson is a Superintendent in the Police Service of Northern Ireland and a graduate of the Police Executive Programme at the University of Cambridge. 